\title{
3 Research Square \\ Sex Differences in Recovery of Motor Function in a Rhesus Monkey Model of Cortical Injury
}

\section{Karen R. Bottenfield ( $\nabla$ karenrb@bu.edu )}

Boston University School of Medicine https://orcid.org/0000-0002-9351-1947

\section{Bethany Bowley}

Boston University School of Medicine

\section{Monica Pessina}

Boston University School of Medicine

\section{Maria Medalla}

Boston University School of Medicine

\section{Douglas Rosene}

Boston University School of Medicine

\section{Tara Moore}

Boston University School of Medicine

\section{Research}

Keywords: motor cortex, injury, stroke, recovery, sex, estrogen, rhesus, monkey, ischemia, hand

Posted Date: May 11th, 2021

DOI: https://doi.org/10.21203/rs.3.rs-499618/v1

License: (c) (i) This work is licensed under a Creative Commons Attribution 4.0 International License. Read Full License

Version of Record: A version of this preprint was published at Biology of Sex Differences on October 9th, 2021. See the published version at https://doi.org/10.1186/s13293-021-00398-9. 


\section{Abstract}

Background: Stroke disproportionately affects men and women, with women over 65 experiencing increased severity of impairment and higher mortality rates than men. Human studies have explored risk factors that contribute to these differences, but additional research is needed to investigate how sex differences affect functional recovery and hence the severity of impairment. In the present study, we used our non-human primate model of cortical injury and fine motor impairment to compare sex differences in the rate and degree of motor recovery following this injury.

Methods: Aged male and female rhesus monkeys were trained on a task of fine motor function of the hand before undergoing surgery to produce a cortical lesion limited to the hand area representation of the primary motor cortex. Post-operative testing began two weeks after the damage and continued for 12 weeks. All trials were video recorded and latency to retrieve a reward was quantitatively measured to assess the trajectory of post-operative response latency and grasp pattern compared to pre-operative levels.

Results: Postmortem analysis showed no differences in lesion volume between male and female. However, females returned to their pre-operative latency and grasp patterns significantly faster than males. To further investigate this finding, we also performed a correlation analyses comparing preoperative estrogen levels in the females with all measures of recovery. No significant relationship was found.

Conclusions: These findings demonstrate the need for additional studies to further investigate the role of estrogen and other sex hormones that may differentially affect recovery outcomes in the primate brain.

\section{Highlights}

- Aged female and male rhesus monkeys were trained on a fine motor task before undergoing surgery to produce a lesion to the hand area representation of the primary motor cortex

- Aged female monkeys returned to pre-operative latency and grasp patterns faster than aged males after cortical injury

- Pre-operative estrogen levels of female monkeys did not correlate with recovery

\section{Background}

According to Framingham Heart Study data, 1 in 5 women over the age of 55 will experience a stroke in their lifetime [1, 2]. Further, it has been established that females experience more severe strokes and have a greater functional impairment and higher mortality rate than males [2-7]. However, prior to advanced age ( 65 years), the incidence of stroke is higher in males than in females $[1,8]$. This has been attributed to the neuroprotective effects of estrogen, especially $17 ß$-estradiol (E2), which is present in higher levels in young compared to aged females [9]. For example, Simpkins et al. (1997) showed that young female 
rats with normal levels of estrogen sustained less neuronal damage following stroke than young males. Further, middle cerebral artery occlusion (MCAOs) in spontaneous hypertensive female rats during proestrus periods (high circulating estradiol) resulted in less cortical damage than MCAO during metestrus (low circulating estradiol) [11]. Also, infarct size in female animals pre-treated with physiological levels of E2 prior to MCAO was more than $50 \%$ smaller than in animals without pretreatment $[10,12,13]$. These studies and many others have established that estrogen plays a role in reducing infarct size and improves functional outcome following ischemia.

Estrogen has anti-inflammatory properties and plays a role in plasticity following injury [14-21]. Estrogen acts on ER- $\alpha$ and ER- $\beta$ receptors expressed on neurons, astrocytes, and microglia to modulate the inflammatory response and promote repair cascades in rodents [12,17, 18, 20,22, 23]. A large body of evidence from studies in rodents and in vitro cultures demonstrates sex differences in the immune cells and oxidative stress pathways mediating these inflammatory and repair responses after injury $[12,22$, 24-26]. However, how these sex differences affect the precise nature and degree of recovery after cortical injury is not well understood in the aged primate brain.

Despite considerable evidence of the effect of estradiol on recovery and inflammation following cortical injury [14-20,27], there have been limited studies looking at cortical injury and recovery in the female brain in a higher order, gyrencephalic animal species. Further, while epidemiological studies in humans have shed light on sex differences in the clinical risk and severity of stroke, variability in the human datasets precludes precise quantitative studies and establishment of predictive models of how sex affects severity of functional impairments and degree of recovery after injury. Our group has successfully established a non-human primate (NHP) model of cortical injury [28] in which we determined the degree of impairment and the rate and pattern of recovery of function following cortical injury in young and middle-aged male rhesus monkeys. In this model of cortical injury, a targeted lesion is made in the hand representation of the primary motor cortex to quantify the extent of impairment and subsequent progression of recovery of fine motor hand movement [28-31]. In the present study, using this model, we now compare the rate and pattern of recovery of function following cortical injury in aged male and female monkeys. Data from this study provide insight into the rate and extent of recovery in response to cortical injury in the female monkey brain compared to the male rhesus monkeys.

\section{Methods}

\section{Animals}

Four male and five female aged rhesus monkeys (Macaca mulatta) (16-26 years, equivalent to approximately 48-78 year-old humans) [32] were used in this study. Monkeys were obtained from national primate research facilities or private vendors and had known birth dates and complete health records. Monkeys received medical examinations and magnetic resonance imaging to ensure there was no occult health problems or neurological damage. Monkeys were housed in the Animal Science Center 
of Boston University School of Medicine which is AAALAC accredited. All procedures were approved by the Boston University Institutional Animal Care and Use Committee.

\section{Pre-operative training on fine motor function testing}

As described in detail previously [30,33], monkeys were trained on a task of fine motor function of the hand, the Hand Dexterity Task (HDT), using a testing apparatus that controls, quantifies and video records responses from each hand. Using this apparatus, monkeys were trained on the HDT for a total of 12 days (Monday, Wednesday and Friday each week for 4 weeks). The HDT is a modified version of a Klüver board [34] and requires precise control of the digits, particularly apposition of the thumb and index finger, to efficiently retrieve a small, visible food reward (M\&M's, Mars, Inc.) from two different size round wells in a Plexiglas tray. Food rewards were round and approximately $1 \mathrm{~cm}$ in diameter. Both wells were 1 $\mathrm{cm}$ deep. The large well was $25 \mathrm{~mm}$ wide and the small well was $18 \mathrm{~mm}$ wide. Time to retrieve the food reward is recorded by a timer connected to photocells located in the openings on each side of the apparatus that allow hand access to the baited wells. The timer starts when the monkey puts a hand through the opening, triggering the photocells to start the timer. The timer stops when the monkey removes its hand. An experimenter records whether or not the reward is successfully retrieved and the response time to retrieve is recorded. The HDT has been used to assess fine motor function of the hand and digits in adult monkeys with and without injury to the hand representation in the motor cortex, as well as to compare the performance of middle-aged rhesus monkeys to young adult monkeys [28,33]. Each test day consists of 16 trials for each of the two well sizes as well as for each hand resulting in a total of 32 trials. The order of trials for each hand and well follows a pseudorandom balanced sequence to eliminate any order effects. Monkeys are given 30 seconds to complete a trial. If they do not complete a trial in $30 \mathrm{sec}$, the trial is terminated, and the monkey is given one additional opportunity to complete that trial. After a second failed attempt, a non-response is recorded, the monkey's difficulties are noted in the study record, and the next trial is initiated.

\section{Hand preference}

At the completion of pre-operative training on the HDT, free choice trials with both sides of the apparatus baited and accessible are administered to determine which hand is "preferred". This assessment is also compared with the pre-operative response latencies for each hand. Based on this assessment, the cortical injury is targeted to the hand representation of the hemisphere controlling the preferred hand. This ensures that monkeys are motivated to use the impaired hand during post-operative testing.

\section{Electrophysiological mapping of the hand representation in motor cortex}

All surgical procedures are carried out under aseptic conditions. Description of surgical procedure is reported in detail in Moore et al, 2019. In brief, the head is stabilized in a stereotactic apparatus, and a midline incision made followed by reflection of the temporalis muscle. A bone flap approximately $40 \mathrm{~mm}$ in anterior to posterior extent and $35 \mathrm{~mm}$ in medial to lateral extent is made centered over the precentral 
gyrus. The bone is removed in one piece and replaced at the end of surgery. The dura is incised to expose the precentral sulcus and primary motor cortex.

To create reproducible cortical injury and motor deficits limited to the hand, a calibrated photograph of the pre-central gyrus is taken and printed. The precentral gyrus was then systematically explored using electrical stimulation delivered through a small monopolar silver ball electrode placed gently on the surface of the pia to evoke movements. A surface electrode is used rather than a sharp electrode that penetrates the cortex in order to avoid extraneous damage to the motor cortex outside the hand representation. The stimulating electrode is moved across the precentral gyrus systematically in rows spaced approximately $2 \mathrm{~mm}$ apart ventral to dorsal with each stimulation site in the row separated by $2 \mathrm{~mm}$ in anterior to posterior as shown in Fig. 1. Monopolar stimulus pulses of $250 \mu \mathrm{sec}$ duration at amplitudes from 2.0 to $3.0 \mathrm{~mA}$ are delivered at each site once every 2 seconds first singly and then in a short train of 4 pulses at a rate of $100 \mathrm{~Hz}$. Non-responsive sites are further tested with a $200 \mathrm{~Hz}$ train consisting of 4 or 8 pulses of 2 msec duration. During each stimulation, a trained observer notes muscle movement (e.g. distinct movement or twitches of muscle) in specific areas of the digits, hand, forearm or arm, both visually and by palpation. The intensity of the motor response in the hand and digits is graded on a scale of 1 to 3 (barely visible to maximal). Specific stimulation sites with the lowest threshold and highest motor response are marked on the calibrated photograph creating a cortical surface map of the hand area that is used to guide placement of the lesion (Fig. 1).

\section{Placement of selective cortical injury}

Using the map described above, cortical injury is induced by making a small incision in the pia at the dorsal limit of the mapped representation. A small glass suction pipette is then inserted under the pia and used to bluntly transect the small penetrating arterioles as they leave the pia and enter the underlying cortex. Suction and irrigation with sterile saline are sufficient to stanch any bleeding and maintain a clear field. Since the hand representation is known to extend down the rostral bank of the central sulcus, the central sulcus is opened along the length of the gyral hand representation and exposed down to the fundus by microdissection with a small glass pipette and a blunt periosteal elevator. As on the surface, the pia is then dissected with the glass pipette down to the fundus on the rostral bank of the sulcus taking care to leave the somatosensory cortex on the caudal bank intact. For the same reason, the hand area in the sulcus is not electrophysiologically mapped with the electrode to avoid inadvertent damage to the somatosensory as this mapping would require prolonged retraction. However, we have verified electrophysiologically in terminal experiments the presence of the hand representation on the rostral bank beneath to gyral representation. The pial dissection of penetrating vessels removes the blood supply to the cortex of the hand representation, inducing damage that extends down to the underlying white matter. Representative photos of the cortical map and lesion for one male and one female monkey are shown in Fig. 1.

\section{Post-operative testing}


Post-operative testing on the HDT begins two weeks after surgery and continued for 12 weeks. As in preoperative testing this is conducted on Monday, Wednesday, and Friday of each week. However, postoperatively $70 \%$ of the trials are given to side of the impaired hand, while $30 \%$ are given to the intact hand. The $30 \%$ of trials given to the unimpaired hand provide sufficient rewards to maintain motivation and sufficient data to demonstrate that effects are not due to generalized changes in motivation or motor function. The forced use of the impaired hand on $70 \%$ of the trials is similar in nature to constraintinduced therapy used in human rehabilitation which forces use of the impaired limbs [35-37]. Each monkey is given 30 seconds to complete a trial as in pre-operative training and this continues for 12 weeks. This time point was chosen as performance on the HDT by monkeys with cortical injury reaches a stable asymptotic level at this time.

\section{Grasp pattern assessment}

While some spontaneous recovery does occur after injury to cortical motor areas controlling the hand and digits, full recovery of digit function is rare. Further, the spontaneous recovery that does occur is largely compensatory in nature and involves mass action of the entire hand rather than a return to pre-injury fine motor function [38]. The development of compensatory grasp falls short of full functional recovery as it still limits normal activities of daily living so the distinction between complete and compensatory recovery is important for assessing new treatments for recovery from stroke or other cortical injury $[39,40]$. To address this, we developed a Non-Human Primate Grasp Assessment Scale (GRAS) to detect and quantify impairments in fine motor function of the hand and evaluate recovery of function of individual digits and precise finger-thumb pinch used by to retrieve food morsels. The GRAS allows us to objectively distinguish between compensatory grasp function and a return to pre-injury fine motor grasp patterns [41].

This GRAS was adapted from the Eshkol-Wachman Movement Notation [42,43] and the Fugl-Meyer Motor Assessment scale [44]. It rates the position of the digits during grasp and the pattern of grasp and release to provide a semi-quantitative measure of maturity of the grasp pattern. The scale includes 8 divided hierarchical stages, for a total of 14 units with the maximum score of 8 reflecting normal grasp patterns (functional pinch between thumb and one individual digit) [41]. To apply the GRAS scale to our monkeys, performance on the HDT during pre-operative training and post-operative testing was recorded with fixed placement cameras (Logitech, Newark, CA). A licensed Occupational Therapist (MAP) who has clinical experience in the treatment of patients with upper extremity impairment following stroke, and a trained research technician (BGEB) analyzed the videotapes using our NHP Grasp Assessment Scale.

\section{Perfusion and lesion assessment}

At the end of the 12 week post-operative period, monkeys were deeply anesthetized with IV sodium pentobarbital ( $25 \mathrm{mg} / \mathrm{kg}$ to effect) and euthanized by exsanguination during transcardial perfusion of the brain, first for no more than 5 minutes with $4^{\circ} \mathrm{C}$ Krebs buffer at $\mathrm{pH} 7.4$ and then with 8 liters of $37^{\circ} \mathrm{C} 4 \%$ paraformaldehyde, $(\mathrm{pH} 7.4)$ over 10 minutes to completely fix the brain. The skull was opened and the 
brain was photographed in situ with the photograph aligned to the perspective of the cortical map used to create the lesion. The brain was blocked in situ in the coronal plane to ensure reproducible planes of section during later processing. The brain was removed from the skull, weighed and post-fixed overnight in $4 \%$ paraformaldehyde for no more than 18 hours. To eliminate freezing artifact, the brain was then transferred to cryoprotectant solutions of glycerol and buffer and flash frozen at $-75^{\circ} \mathrm{C}$ and stored at $-80^{\circ}$ $\mathrm{C}$ [45]. Frozen blocks were later removed from storage and cut on a sliding microtome into interrupted series of coronal sections (eight series of $30 \mu \mathrm{m}$ thick sections and one $60 \mu \mathrm{m}$ thick series, with $300 \mu \mathrm{m}$ spacing between sections). The $60 \mu \mathrm{m}$ series was immediately mounted on microscope slides and stained with thionin for lesion reconstruction. Other series were collected in buffer with $15 \%$ glycerol, equilibrated overnight at $4^{\circ} \mathrm{C}$ and stored at $-80^{\circ} \mathrm{C}$ for later histochemical processing [46]. Lesion volume was determined for all of the monkeys as described in Go et al., 2019 and Moore et al., 2019.

\section{Results}

\section{Pre-operative Performance}

To establish baseline performance, the mean latency to retrieve across the last 5 days of pre-operative training was calculated for each subject. There was no significant difference between the male and female monkeys in performance on the small well $[F(1,8)=0.396, p=0.549]$ or the large well $[F(1,8)=$ $0.145, p=0.7189]$ (Table 1).

\section{Post-operative Latencies in Females Compared to Males}

Figure 2 shows the mean time to retrieve the food reward each day during the entire 12 week postoperative testing period for each monkey with the dashed line on each graph delineating the pre-operative baseline.

As shown in Fig 3, the mean latency to retrieve the food reward during the $1^{\text {st }}$ five days of post-operative testing ( $3^{\text {rd }}$ week post-injury) was analyzed with a one-way ANOVA for the effect of sex. At this very early stage in the post-operative recovery period female monkeys retrieved the food reward at a faster rate than male monkeys on the large well $[F(1,8)=5.75, p=0.04]$, but not the small well $[F(1,8)=2.70, p=0.144]$. However, at the end of the 12-week post-operative testing period, eight of the nine monkeys had not returned to their baseline pre-operative latencies to retrieve.

In addition, as shown in Table 2, the difference in performance on the first 5 days of post-operative testing relative to the last 5 days of pre-operative testing, showed that female monkeys were significantly less impaired in latency to retrieve than the male monkeys after injury on the large well $[F(1,8)=11.20$, $p$ $=0.01]$, but not on the small well $[F(1,8)=2.97, p=0.128]$ (Fig. 4) early in the recovery period. Taken together, these findings suggest that overall female monkeys experienced less severe deficits in latency to retrieve a food reward after injury than male monkeys.

\section{Post-operative Grasp Assessment Rating in Females Compared to Males}


While the latency to retrieve a food reward is an important measure of recovery, the quality of grasp demonstrated by the monkeys is critical for assessing human recovery of function as return to preoperative grasp function will better allow for successful completion of activities of daily living than a compensatory grasp pattern. In order to determine the extent of recovery of pre-operative grasp in males versus females, we used our Non-Human Primate Grasp Assessment Scale (GRAS) to quantify fine motor function of the hand and to evaluate recovery of function of individual digits and precise finger-thumb pinch used by monkeys to retrieval of food rewards. Figure 5 shows the mean grasp rating each day during the post-operative testing period for each monkey (a score of 8 represents a return to pre-operative grasp patterns). A one-way ANOVA compared the highest level of grasp rating achieved by the monkeys and revealed a significant difference between males and females, with female monkeys achieving an overall higher rating than the male monkeys $[F(1,8)=17.91, p=0.004]$ (Fig 6). Furthermore, four of the five female monkeys returned to their pre-operative grasp pattern (a score of 8 on the GRAS) while none of the male monkeys returned to their pre-operative grasp, but instead demonstrated only compensatory grasp patterns.

\section{Less days to return to pre-operative grasp patterns in females compared to males}

Figure 7 shows the mean numbers of post-operative testing days for monkeys to return to pre-operative grasp patterns (a score of 8 on the GRAS) or to reach an asymptotic level of performance (three consecutive testing days at the highest achieved rating). A one-way ANOVA revealed that the female monkeys reached their highest rating in significantly fewer days than the male monkeys $[F(1,8)=6.67, p$ $=0.04]$.

Representative images in Figure 8 show digit use of the impaired hand from one female monkey (showing the use of a finger-thumb pinch pre-operative grasp) and one male monkey (showing a compensatory grasp). Panel A shows a precise finger-thumb grasp that is representative of a greater degree of recovery of function. This grasp shows isolated digit action and no evidence of "mass action" of the digits or compensatory scooping. Panel B shows compensatory "scooping" involving mass action of all fingers working together to retrieve the food reward and is considered a compensatory grasp pattern. The arrow in panel B shows fingers scooping candy into palm of the hand.

It is of interest to note that during post-operative testing, retrieval from the large well is more difficult than retrieval from the small well due to the fact that, in general, the compensatory scooping grasp is more effective in scooping the reward out of the smaller diameter well. The monkeys are able to steady the treat on the side of the well and then scoop it into their palm. In the larger diameter well, this compensatory movement was more difficult in the larger space as the reward would "slip" away from the monkey while trying to scoop it out of the well without effective finger-thumb apposition. Therefore, the significant difference in performance between the male and female monkeys on the large well, further supports that the female monkeys were less impaired following injury to the hand representation of the primary motor cortex. Specifically, the male monkeys developed a compensatory grasp while the female monkeys returned to pre-operative grasp patterns. 


\section{No significant sex differences in estrogen levels}

Immediately prior to inducing the cortical lesion blood samples were collected to quantify estrogen levels in the female monkeys. A correlation analysis comparing estrogen levels in the female monkeys to all measures of recovery revealed no significant relationship. While the number of monkeys in this group is small, this analysis indicates that estrogen levels were not associated with degree and pattern of recovery observed in these monkeys. However, estrogen levels were not quantified during the entire post-operative testing period and therefore, it cannot be concluded that estrogen levels were not directly involved in recovery processes.

\section{No significant sex differences in lesion volume}

A one-way ANOVA was used to compare the volume of the lesion between the male and female monkeys. Results revealed no significant differences between groups $[F(1,8)=4.59, p=0.07]$ (Table 1).

\section{Discussion}

Overall, the findings from this study demonstrated that female monkeys evidenced less severe impairment of fine motor function of the hand and digits after a cortical injury in primary motor cortex than male monkeys even though the volume of the lesions did not differ. Specifically, female monkeys showed less severe impairments early in the recovery period and a more complete recovery of grasp function than male monkeys.

While a return to pre-injury levels of motor performance is rare in animal models and humans, it was of particular interest in the present study that four of the five female monkeys did return to a precise fingerthumb grasp rather in place of the compensatory grasp patterns observed in the male monkeys. While the development of a compensatory grasp pattern by the male monkeys did achieve the goal of retrieving the food reward on our motor task, this type of compensatory grasp, which is often observed in human stroke patients, is inefficient and does not translate into effective fine motor function of the digits that is required for successful completion of activities of daily living. Therefore, determining the underlying mechanisms of the less severe impairment and the greater degree of recovery of grasp pattern in the female monkeys is of critical importance.

\section{Sex differences in the pathogenesis of cortical injury}

The pathogenesis of cortical injury is characterized by a cascade initiated by acute cellular damage, eventually leading to a sustained inflammatory response, chronic accumulation of oxidative stress, and secondary damage, which impairs cortical reorganization and recovery [49-52]. The brain inflammatory cells, microglia and astrocytes, release several cytotoxic agents including matrix metalloproteinases, nitric oxide, and reactive oxygen species (ROS) which lead to cell death [51,53-55]. The immune response following cortical injury involves increases in reactive astrocytes and microglia that produce 
ROS and inflammatory cytokines and chemokines [50-52,54,56], which can also disrupt neuronal recovery and reorganization.

A large body of evidence from studies in rodents demonstrates sex differences in these immune responses to cortical injury [12,22,24-26,57]. In rodents, a diminished pro-inflammatory response associated with a lower density of amoeboid (activated) microglia was found in females compared to males after recovery from ischemic injury [58-60]. Additionally, male neurons and astrocytes are more sensitive to ischemia and oxygen-glucose deprivation than female cells in vitro [57,61-63]. In response to the inflammatory agent, lipopolysaccharide, male astrocytes show enhanced expression of proinflammatory cytokines, IL6, TNF-alpha and IL1B, while female astrocytes show enhanced expression of the anti-inflammatory cytokine, IL10 $[64,65]$. Further, there is decreased ROS production in astrocytes in female brains compared to male brains [66-68]. In addition to these inflammatory responses, studies with cell cultures have demonstrated sex specific neuronal death mechanisms. For instance, cell death after ischemia in primary neuronal cultures derived from male brains are mediated by excessive ROS production and over-activation of poly(ADP) ribose polymerase (PARP) while death of cells from female brains involves programmed caspase-dependent apoptosis [27,69-73].

One potential mechanism underlying age-dependent sex differences is the release of estrogen following brain injury. As a neuroprotective agent, E2 acts on ER-a, and ER-b receptors expressed by neurons, astrocytes, and microglia to modulate inflammation and promote plasticity $[12,16,22,24,25,74]$. Acute estradiol treatment increases spine density and stabilization of newly formed spines through recruitment of synaptic proteins and receptors in cultured cortical neurons [20]. In rodent and monkey studies, estradiol treatment has shown to play an important role in rescuing age-related synaptic plasticity by modulating actin and synapse formation [75-77]. In addition, estrogen stimulates neuronal survival by altering the expression of the anti-apoptotic gene, $b c l-2$ that inhibits free radical formation [22]. Further, estrogen can reduce inflammation through interactions with neurotrophic factors and by directly acting on the ER-a receptors on astrocytes and microglia [12,24,26,66,78-80]. Astrocytes express estrogen receptors and produce estradiol in both males and females [80,81]. Following cortical injury, astrocytederived estradiol mediates anti-inflammatory effects through the release of neurotrophic factors, BDNF, IGF-1, and GLT-1, as the astrocytes become reactive and increase expression of ER-a receptors and glial fibrillary acidic protein (GFAP) $[9,23,74,78,82-86]$.

\section{Estrogen levels in aged rhesus monkeys}

While there is substantial evidence that acute estrogen treatment in vitro and increased estrogen after injury in vivo in rodents lead to neuroprotection, how the cyclical changes in estrogen influence susceptibility to injury is not clear. Here we show no significant linear relationships between pre-operative, baseline estrogen levels at the time of cortical injury and any of the recovery measures, which suggests that undetected multivariate cyclical hormonal factors may be a factor. There are varied definitions of menopause in humans, ranging from criterion such a permanent cessation of menstruation and cessation of steroid hormone secretion $[87,88]$. However, what is most commonly considered criterion for 
menopause is the permanent, non-pathologic, age-associated cessation of ovulation as measured by increases in follicle stimulating hormone (FSH) couple with decreases in anti-Mullerian hormone (AMH), inhibin $B$, and estradiol $[89,90]$. Using this criterion, most studies place the mean age of menopause in humans at approximately 50 years of age. However, the criterion and age of onset of menopause and age-associated hormonal levels are less clear in the rhesus monkey due to the effects of captivity, controlled laboratory and housing environments, and seasonal breeding in this species [87]. Given these challenges, estimates for age of menopause in captive rhesus monkeys have ranged from 22-27 years of age [91-93]. The monkeys in the current study ranged from 20-26 years of age and were therefore likely undergoing age-related reductions in $\mathrm{FSH}, \mathrm{AMH}$, inhibin $\mathrm{B}$, and estradiol [87,93-95] which may in part explain why there was a no significant linear relationship between degree of recovery and estrogen levels at time of cortical injury. Further, we did not monitor post-operative estrogen levels throughout the recovery period and therefore cannot assess whether increases in estrogen levels induced by injury may have facilitated recovery.

\section{Sex Differences in Human Stroke and Recovery}

While our model does not replicate stroke per se, it does model the injury and inflammatory cascade that occurs following stroke and therefore provides insight about recovery of function, plasticity, and repair in the brain and potential sex differences in these recovery processes. Regarding sex differences in humans, there is a higher incidence of stroke in males until the age of 65 years. Afterwards, the prevalence and severity of stroke among females significantly increases $[2,4-6,8,96]$. This shift during advanced age is attributed to decreases in estrogen and its corresponding neuroprotective effects, especially $17 ß$-estradiol (E2) [9].

Clinical studies demonstrate considerable evidence that post-menopausal females experience greater stroke severity than their male counterparts, but differences in functional recovery remain unclear. For example, it has been shown that males experience a greater relative loss of muscle strength than females when post-stroke upper extremity muscle strength in the affected limb is reported as a percentage of strength of the unaffected side [97]. However, most studies demonstrate an overall lesser degree of physical recovery in females $[2,4,96,98-101]$. The degree of recovery after stroke or other brain injuries is often assessed in large clinical trials by evaluating activities of daily living (ADL) using the Barthel Index (BI) or the modified Rankin scale (mRS) [102]. Both scales are widely used, but are frequently challenged by questions of subjectivity, reliability, and sensitivity [102,103]. In addition, the scales do not assess the level of return to pre-injury motor function, but instead only measure independence level while performing daily tasks or routines. Since males typically experience stroke at a younger age than females, the difference in scores is often explained by males having more assistance with ADLs from a spouse, while females are more likely to be widowed at the time they experience a stroke $[2,100,104]$. Thus, the independence levels reported by women are often lower and associated with less assistance at home to perform their tasks [104]. Clinical studies are further challenged by other social and biological factors that include confounding factors such as mental health, lifestyle, comorbid risk factors (i.e., cardiovascular disease, diabetes mellitus, hypertension, etc.), household expectations, and family support $[4,6]$. 


\section{Perspectives and Significance}

Currently, there is no consensus on outcome measures that can provide a more complete and quantitative assessment of post-stroke recovery in human females compared to males [105]. Despite the clinical and epidemiological evidence of sex differences, the variability and confounding factors inherent to clinical studies affirms the importance of translatable models that can provide quantitative analyses of functional impairment and recovery after injury.

\section{Conclusions}

Overall, female monkeys in this study showed less severe impairment and more complete recovery than male monkeys even though there were no differences in the lesion volume. Estrogen levels were measured immediately prior to inducing cortical damage and had no significant association with any measures of recovery. This lack of a relationship may be due to the small sample size in this study. Alternatively, though the estrogen levels were within normal ranges, these monkeys were within the age range that perimenopause or full menopause can begin and multivariate cyclical hormonal changes are likely at play. The estrogen levels assessed pre-operatively may not have been representative of those circulating during the period of post-operative recovery. It is also possible that there may be a threshold effect where there was sufficient estrogen to facilitate recovery compared to males. Alternatively, observed individual difference in measures of recovery may also have been due to other hormonal factors such as progesterone which is also involved in providing neuroprotection in the female brain [106-109]. A complete explanation of the present results of reduced severity of impairment and enhanced recovery of function in females will require more mechanistic studies with the use of estrogen supplementation constituting one important avenue for future investigation.

\section{Declarations}

\section{Ethics approval}

All procedures with animals were conducted in accordance with state and federal laws and were approved by the Boston University Institutional Animal Care and Use Committee.

\section{Consent for publication}

Not applicable

\section{Availability of data and materials}

All data generated and/or analyzed during this study are included in this published article.

\section{Competing interests}

The authors declare that they have no competing interests. 


\section{Funding}

This work was supported by NIH-NINDS R21NS102991, NIH-NINDS R21NS111174 and NIH-NIA R21AG028680.

\section{Authors' contributions}

BB and MP reviewed and scored grasp data. TM analyzed latency and grasp data. KB and TM wrote the manuscript. MM, MP, TM, and DR contributed to editing the manuscript. All authors read and approved the final manuscript.

\section{Acknowledgements}

The authors wish to thank Karen Slater, Katelyn Trecartin, Ajay Uprety, Veronica Go, Penny Shultz and Ethan Gaston for their invaluable assistance with this project.

\section{References}

1. Seshadri S, Beiser A, Kelly-Hayes M, Kase CS, Au R, Kannel WB, et al. The lifetime risk of stroke: estimates from the Framingham Study. Stroke. 2006;37(2):345-50. https://doi.org/10.1161/01.STR.0000199613.38911.b2.

2. Petrea RE, Beiser AS, Seshadri S, Kelly-Hayes M, Kase CS, Wolf PA. Gender Differences in Stroke Incidence and Poststroke Disability in the Framingham Heart Study. Stroke. 2009;40(4):1032-7. https://doi.org/10.1161/STROKEAHA.108.542894.

3. Andersen MN, Andersen KK, Kammersgaard LP, Olsen TS. Sex Differences in Stroke Survival: 10-Year Follow-up of the Copenhagen Stroke Study Cohort. Journal of Stroke Cerebrovascular Diseases. 2005;14(5):215-20. https://doi.org/10.1016/j.jstrokecerebrovasdis.2005.06.002.

4. Lai S-M, Duncan PW, Dew P, Keighley J. Sex differences in stroke recovery. Prev Chronic Dis. 2005;2(3):A13.

5. Appelros P, Stegmayr B, Terént A. A review on sex differences in stroke treatment and outcome: Sex differences in stroke treatment and outcome. Acta Neurol Scand. 2009;121(6):359-69. https://doi.org/10.1111/j.1600-0404.2009.01258.x.

6. Fukuda M, Kanda T, Kamide N, Akutsu T, Sakai F. Gender Differences in Long-term Functional Outcome after First-ever Ischemic Stroke. Intern Med. 2009;48(12):967-73. https://doi.org/10.2169/internalmedicine.48.1757.

7. Manwani B, McCullough LD. Sexual Dimorphism in Ischemic Stroke: Lessons from the Laboratory. Womens Health (Lond Engl). 2011;7(3):319-39. https://doi.org/10.2217/WHE.11.22.

8. Roger VL, Go AS, Lloyd-Jones DM, Adams RJ, Berry JD, Brown TM, et al. Heart Disease and Stroke Statistics-2011 Update: A Report From the American Heart Association. Circulation. 2011;123(4). https://doi.org/10.1161/CIR.0b013e3182009701. 
9. Schreihofer DA, Ma Y. Estrogen receptors and ischemic neuroprotection: Who, what, where, and when? Brain Res. 2013;1514:107-22. https://doi.org/10.1016/j.brainres.2013.02.051.

10. Simpkins JW, Green PS, Gridley KE, Singh M, de Fiebre NC, Rajakumar G. Role of Estrogen Replacement Therapy in Memory Enhancement and the Prevention of Neuronal Loss Associated With Alzheimer's Disease. The American Journal of Medicine. 1997;103(3):19S-25S. https://doi.org/10.1016/S0002-9343(97)00260-X.

11. Carswell HVO, Dominiczak AF, Macrae IM. Estrogen status affects sensitivity to focal cerebral ischemia in stroke-prone spontaneously hypertensive rats. Am J Physiol Heart Circ Physiol. 2000;278(1):H290-4. https://doi.org/10.1152/ajpheart.2000.278.1.H290.

12. Dubal DB, Kashon ML, Pettigrew LC, Ren JM, Finklestein SP, Rau SW, et al. Estradiol Protects against Ischemic Injury. J Cereb Blood Flow Metab. 1998;18(11):1253-8. https://doi.org/10.1097/00004647$199811000-00012$.

13. Dubal DB, Wise PM. Neuroprotective effects of estradiol in middle-aged female rats. Endocrinology. 2001;142(1):43-8. https://doi.org/10.1210/endo.142.1.7911.

14. Kreutzberg GW. Microglia: a sensor for pathological events in the CNS. Trends Neurosci. 1996;19(8):312-8. https://doi.org/10.1016/0166-2236(96)10049-7.

15. Haley PJ. Species differences in the structure and function of the immune system. Toxicology. 2003;188(1):49-71. https://doi.org/10.1016/s0300-483x(03)00043-x.

16. Brann DW, Dhandapani K, Wakade C, Mahesh VB, Khan MM. Neurotrophic and neuroprotective actions of estrogen: basic mechanisms and clinical implications. Steroids. 2007;72(5):381-405. https://doi.org/10.1016/j.steroids.2007.02.003.

17. Guo J, Duckles SP, Weiss JH, Li X, Krause DN. 17ß-Estradiol prevents cell death and mitochondrial dysfunction by an estrogen receptor-dependent mechanism in astrocytes after oxygen-glucose deprivation/reperfusion. Free Radic Biol Med. 2012;52(11-12):2151-60. https://doi.org/10.1016/j.freeradbiomed.2012.03.005.

18. Arevalo MA, Santos-Galindo M, Acaz-Fonseca E, Azcoitia I, Garcia-Segura LM. Gonadal hormones and the control of reactive gliosis. Horm Behav. 2013;63(2):216-21. https://doi.org/10.1016/j.yhbeh.2012.02.021.

19. Sohrabji F, Bake S, Lewis DK. Age-related changes in brain support cells: Implications for stroke severity. Neurochem Int. 2013;63(4):291-301. https://doi.org/10.1016/j.neuint.2013.06.013.

20. Sellers KJ, Erli F, Raval P, Watson IA, Chen D, Srivastava DP. Rapid modulation of synaptogenesis and spinogenesis by 17ß-estradiol in primary cortical neurons. Front Cell Neurosci. 2015;9:137. https://doi.org/10.3389/fncel.2015.00137.

21. Du Y, Deng W, Wang Z, Ning M, Zhang W, Zhou Y, et al. Differential subnetwork of chemokines/cytokines in human, mouse, and rat brain cells after oxygen-glucose deprivation. $\mathrm{J}$ Cereb Blood Flow Metab. 2017;37(4):1425-34. https://doi.org/10.1177/0271678X16656199.

22. Dubal DB, Wilson ME, Wise PM. Estradiol: a protective and trophic factor in the brain. J Alzheimers Dis. 1999;1(4-5):265-74. https://doi.org/10.3233/jad-1999-14-507. 
23. Lu Y, Sareddy GR, Wang J, Zhang Q, Tang F-L, Pratap UP, et al. Neuron-Derived Estrogen Is Critical for Astrocyte Activation and Neuroprotection of the Ischemic Brain. J Neurosci. 2020;40(38):7355-74. https://doi.org/10.1523/JNEUROSCI.0115-20.2020.

24. Wise PM, Dubal DB, Wilson ME, Rau SW, Liu Y. Estrogens: trophic and protective factors in the adult brain. Front Neuroendocrinol. 2001;22(1):33-66. https://doi.org/10.1006/frne.2000.0207.

25. Vegeto E, Belcredito S, Etteri S, Ghisletti S, Brusadelli A, Meda C, et al. Estrogen receptor-alpha mediates the brain antiinflammatory activity of estradiol. Proc Natl Acad Sci U S A. 2003;100(16):9614-9. https://doi.org/10.1073/pnas.1531957100.

26. Vegeto E, Belcredito S, Ghisletti S, Meda C, Etteri S, Maggi A. The endogenous estrogen status regulates microglia reactivity in animal models of neuroinflammation. Endocrinology. 2006;147(5):2263-72. https://doi.org/10.1210/en.2005-1330.

27. Du L, Bayir H, Lai Y, Zhang X, Kochanek PM, Watkins SC, et al. Innate gender-based proclivity in response to cytotoxicity and programmed cell death pathway. J Biol Chem. 2004;279(37):38563-70. https://doi.org/10.1074/jbc.M405461200.

28. Moore TL, Killiany RJ, Pessina MA, Moss MB, Finklestein SP, Rosene DL. Recovery from ischemia in the middle-aged brain: a nonhuman primate model. Neurobiol Aging. 2012;33(3):619.e9-619.e24. https://doi.org/10.1016/j.neurobiolaging.2011.02.005.

29. Moore TL, Pessina MA, Finklestein SP, Kramer BC, Killiany RJ, Rosene DL. Recovery of fine motor performance after ischemic damage to motor cortex is facilitated by cell therapy in the rhesus monkey. Somatosens Mot Res. 2013;30(4):185-96. https://doi.org/10.3109/08990220.2013.790806.

30. Moore TL, Pessina MA, Finklestein SP, Killiany RJ, Bowley B, Benowitz L, et al. Inosine enhances recovery of grasp following cortical injury to the primary motor cortex of the rhesus monkey. Restor Neurol Neurosci. 2016;34(5):827-48. https://doi.org/10.3233/RNN-160661.

31. Moore TL, Bowley BGE, Shultz PL, Calderazzo SM, Shobin EJ, Uprety AR, et al. Oral curcumin supplementation improves fine motor function in the middle-aged rhesus monkey. Somatosens Motor Res. 2018;1-10. https://doi.org/10.1080/08990220.2018.1432481.

32. Tigges J, Gordon TP, McClure HM, Hall EC, Peters A. Survival rate and life span of rhesus monkeys at the Yerkes regional primate research center. Am J Primatol. 1988;15(3):263-73. https://doi.org/10.1002/ajp.1350150308.

33. Moore TL, Killiany RJ, Pessina MA, Moss MB, Rosene DL. Assessment of motor function of the hand in aged rhesus monkeys. Somatosens Mot Res. 2010;27(3):121-30. https://doi.org/10.3109/08990220.2010.485963.

34. Kluver H. An auto-multi-stimulation reaction board for use with sub-human primates. The Journal of Psychology: Interdisciplinary Applied. 1935;1:123-7.

35. Corbetta M, Ramsey L, Callejas A, Baldassarre A, Hacker CD, Siegel JS, et al. Common Behavioral Clusters and Subcortical Anatomy in Stroke. Neuron. 2015;85(5):927-41. https://doi.org/10.1016/j.neuron.2015.02.027. 
36. Souza WC, Conforto AB, Orsini M, Stern A, André C. Similar Effects of Two Modified ConstraintInduced Therapy Protocols on Motor Impairment, Motor Function and Quality of Life in Patients with Chronic Stroke. Neurol Int. 2015;7(1):5430. https://doi.org/10.4081/ni.2015.5430.

37. Kwakkel G, Winters C, van Wegen EEH, Nijland RHM, van Kuijk AAA, Visser-Meily A, et al. Effects of Unilateral Upper Limb Training in Two Distinct Prognostic Groups Early After Stroke: The EXPLICITStroke Randomized Clinical Trial. Neurorehabil Neural Repair. 2016;30(9):804-16. https://doi.org/10.1177/1545968315624784.

38. Hylin MJ, Kerr AL, Holden R. Understanding the Mechanisms of Recovery and/or Compensation following Injury. Neural Plast. 2017;2017:1-12. https://doi.org/10.1155/2017/7125057.

39. Levin MF, Kleim JA, Wolf SL. What Do Motor "Recovery" and "Compensation" Mean in Patients Following Stroke? Neurorehabil Neural Repair. 2009;23(4):313-9. https://doi.org/10.1177/1545968308328727.

40. Lum PS, Mulroy S, Amdur RL, Requejo P, Prilutsky BI, Dromerick AW. Gains in Upper Extremity Function After Stroke via Recovery or Compensation: Potential Differential Effects on Amount of Real-World Limb Use. Topics in Stroke Rehabilitation. 2009;16(4):237-53. https://doi.org/10.1310/tsr1604-237.

41. Pessina MA, Bowley BGE, Rosene DL, Moore TL. A method for assessing recovery of fine motor function of the hand in a rhesus monkey model of cortical injury: an adaptation of the Fugl-Meyer Scale and Eshkol-Wachman. Movement Notation Somatosensory Motor Research. 2019;36(1):6977. https://doi.org/10.1080/08990220.2019.1594751.

42. Carr JH, Shepherd RB, Nordholm L, Lynne D. Investigation of a new motor assessment scale for stroke patients. Phys Ther. 1985;65(2):175-80. https://doi.org/10.1093/ptj/65.2.175.

43. Whishaw IQ, Suchowersky O, Davis L, Sarna J, Metz GA, Pellis SM. Impairment of pronation, supination, and body co-ordination in reach-to-grasp tasks in human Parkinson's disease (PD) reveals homology to deficits in animal models. Behav Brain Res. 2002;133(2):165-76. https://doi.org/10.1016/s0166-4328(01)00479-x.

44. Fugl-Meyer AR, Jääskö L, Leyman I, Olsson S, Steglind S. The post-stroke hemiplegic patient. 1. a method for evaluation of physical performance. Scand J Rehabil Med. 1975;7(1):13-31.

45. Rosene DL, Roy NJ, Davis BJ. A cryoprotection method that facilitates cutting frozen sections of whole monkey brains for histological and histochemical processing without freezing artifact. J Histochem Cytochem. 1986;34(10):1301-15. https://doi.org/10.1177/34.10.3745909.

46. Estrada LI, Robinson AA, Amaral AC, Giannaris EL, Heyworth NC, Mortazavi F, et al. Evaluation of Long-Term Cryostorage of Brain Tissue Sections for Quantitative Histochemistry. J Histochem Cytochem. 2017;65(3):153-71. https://doi.org/10.1369/0022155416686934.

47. Go V, Bowley BGE, Pessina MA, Zhang ZG, Chopp M, Finklestein SP, et al. Extracellular vesicles from mesenchymal stem cells reduce microglial-mediated neuroinflammation after cortical injury in aged Rhesus monkeys. Geroscience. 2019. https://doi.org/10.1007/s11357-019-00115-w. 
48. Moore TL, Bowley BGE, Pessina MA, Calderazzo SM, Medalla M, Go V, et al. Mesenchymal derived exosomes enhance recovery of motor function in a monkey model of cortical injury. Restor Neurol Neurosci. 2019;37(4):347-62. https://doi.org/10.3233/RNN-190910.

49. Flamm ES, Demopoulos HB, Seligman ML, Poser RG, Ransohoff J. Free radicals in cerebral ischemia. Stroke. 1978;9(5):445-7. https://doi.org/10.1161/01.STR.9.5.445.

50. Taylor JM, Crack PJ. Impact of oxidative stress on neuronal survival. Clin Exp Pharmacol Physiol. 2004;31(7):397-406. https://doi.org/10.1111/j.1440-1681.2004.04017.x.

51. Wang Q, Tang X, Yenari M. The inflammatory response in stroke. J Neuroimmunol. 2007;184(12):53-68. https://doi.org/10.1016/j.jneuroim.2006.11.014.

52. Lakhan SE, Kirchgessner A, Hofer M. Inflammatory mechanisms in ischemic stroke: therapeutic approaches. J Transl Med. 2009;7(1):97. https://doi.org/10.1186/1479-5876-7-97.

53. Sugawara T, Chan PH. Reactive Oxygen Radicals and Pathogenesis of Neuronal Death After Cerebral Ischemia. Antioxid Redox Signal. 2003;5(5):597-607. https://doi.org/10.1089/152308603770310266.

54. Margaill I, Plotkine M, Lerouet D. Antioxidant strategies in the treatment of stroke. Free Radic Biol Med. 2005;39(4):429-43. https://doi.org/10.1016/j.freeradbiomed.2005.05.003.

55. Patel AR, Ritzel R, McCullough LD, Liu F. Microglia and ischemic stroke: a double-edged sword. Int J Physiol Pathophysiol Pharmacol. 2013;5(2):73-90.

56. Warner DS. Oxidants, antioxidants and the ischemic brain. J Exp Biol. 2004;207(18):3221-31. https://doi.org/10.1242/jeb.01022.

57. Liu M, Hurn PD, Roselli CE, Alkayed NJ. Role of P450 aromatase in sex-specific astrocytic cell death. J Cereb Blood Flow Metab. 2007;27(1):135-41. https://doi.org/10.1038/sj.jcbfm.9600331.

58. Xiong X, Xu L, Wei L, White RE, Ouyang Y-B, Giffard RG. IL-4 is required for sex differences in vulnerability to focal ischemia in mice. Stroke. 2015;46(8):2271-6. https://doi.org/10.1161/STROKEAHA.115.008897.

59. Hanamsagar R, Bilbo SD. Sex differences in neurodevelopmental and neurodegenerative disorders: Focus on microglial function and neuroinflammation during development. J Steroid Biochem Mol Biol. 2016;160:127-33. https://doi.org/10.1016/j.jsbmb.2015.09.039.

60. McCarthy MM, Nugent BM, Lenz KM. Neuroimmunology and neuroepigenetics in the establishment of sex differences in the brain. Nat Rev Neurosci. 2017;18(8):471-84. https://doi.org/10.1038/nrn.2017.61.

61. Heyer A, Hasselblatt $M$, von Ahsen $N$, Häfner $H$, Sirén $A-L$, Ehrenreich $H$. In vitro gender differences in neuronal survival on hypoxia and in 17beta-estradiol-mediated neuroprotection. J Cereb Blood Flow Metab. 2005;25(4):427-30. https://doi.org/10.1038/sj.jcbfm.9600056.

62. Liu M, Oyarzabal EA, Yang R, Murphy SJ, Hurn PD. A novel method for assessing sex-specific and genotype-specific response to injury in astrocyte culture. J Neurosci Methods. 2008;171(2):214-7. https://doi.org/10.1016/j.jneumeth.2008.03.002. 
63. Johnsen D, Murphy SJ. Isoflurane preconditioning protects astrocytes from oxygen and glucose deprivation independent of innate cell sex. J Neurosurg Anesthesiol. 2011;23(4):335-40. https://doi.org/10.1097/ANA.0b013e3182161816.

64. Santos-Galindo M, Acaz-Fonseca E, Bellini MJ, Garcia-Segura LM. Sex differences in the inflammatory response of primary astrocytes to lipopolysaccharide. Biol Sex Differ. 2011;2:7. https://doi.org/10.1186/2042-6410-2-7.

65. Loram LC, Sholar PW, Taylor FR, Wiesler JL, Babb JA, Strand KA, et al. Sex and estradiol influence glial pro-inflammatory responses to lipopolysaccharide in rats. Psychoneuroendocrinology. 2012;37(10):1688-99. https://doi.org/10.1016/j.psyneuen.2012.02.018.

66. Cordeau P, Lalancette-Hébert M, Weng YC, Kriz J. Live imaging of neuroinflammation reveals sex and estrogen effects on astrocyte response to ischemic injury. Stroke. 2008;39(3):935-42. https://doi.org/10.1161/STROKEAHA.107.501460.

67. Sohrabji F, Williams M. Stroke neuroprotection: oestrogen and insulin-like growth factor-1 interactions and the role of microglia. J Neuroendocrinol. 2013;25(11):1173-81. https://doi.org/10.1111/jne.12059.

68. Morrison HW, Filosa JA. Sex differences in astrocyte and microglia responses immediately following middle cerebral artery occlusion in adult mice. Neuroscience. 2016;339:85-99. https://doi.org/10.1016/j.neuroscience.2016.09.047.

69. Lang JT, McCullough LD. Pathways to ischemic neuronal cell death: are sex differences relevant? J Transl Med. 2008;6(1):33. https://doi.org/10.1186/1479-5876-6-33.

70. Yuan M, Siegel C, Zeng Z, Li J, Liu F, McCullough LD. Sex differences in the response to activation of the poly (ADP-ribose) polymerase pathway after experimental stroke. Exp Neurol. 2009;217(1):2108. https://doi.org/10.1016/j.expneurol.2009.02.012.

71. Vagnerova K, Liu K, Ardeshiri A, Cheng J, Murphy SJ, Hurn PD, et al. PARP-1 initiated neuronal cell death pathway-do androgens matter? Neuroscience. 2010;166(2):476-81. https://doi.org/10.1016/j.neuroscience.2009.12.041.

72. Jia J, Verma S, Nakayama S, Quillinan N, Grafe MR, Hurn PD, et al. Sex differences in neuroprotection provided by inhibition of TRPM2 channels following experimental stroke. Journal of cerebral blood flow metabolism: official journal of the International Society of Cerebral Blood Flow Metabolism. 2011;31(11):2160-8. https://doi.org/10.1038/jcbfm.2011.77.

73. Herson PS, Palmateer J, Hurn PD. Biological sex and mechanisms of ischemic brain injury. Translational stroke research. 2013;4(4):413-9. https://doi.org/10.1007/s12975-012-0238-x.

74. Zhang Q-G, Wang R, Tang H, Dong Y, Chan A, Sareddy GR, et al. Brain-derived estrogen exerts antiinflammatory and neuroprotective actions in the rat hippocampus. Mol Cell Endocrinol. 2014;389(12):84-91. https://doi.org/10.1016/j.mce.2013.12.019.

75. Wang ACJ, Hara Y, Janssen WGM, Rapp PR, Morrison JH. Synaptic Estrogen Receptor-a Levels in Prefrontal Cortex in Female Rhesus Monkeys and Their Correlation with Cognitive Performance. $J$ Neurosci. 2010;30(38):12770-6. https://doi.org/10.1523/JNEUROSCI.3192-10.2010. 
76. Hara Y, Waters EM, McEwen BS, Morrison JH. Estrogen Effects on Cognitive and Synaptic Health Over the Lifecourse. Physiol Rev. 2015;95(3):785-807. https://doi.org/10.1152/physrev.00036.2014.

77. Beckman D, Ott S, Donis-Cox K, Janssen WG, Bliss-Moreau E, Rudebeck PH, et al. Oligomeric A $\beta$ in the monkey brain impacts synaptic integrity and induces accelerated cortical aging. Proc Natl Acad Sci USA. 2019;116(52):26239-46. https://doi.org/10.1073/pnas.1902301116.

78. Arevalo MA, Santos-Galindo M, Lagunas N, Azcoitia I, Garcia-Segura LM. Selective estrogen receptor modulators as brain therapeutic agents. J Mol Endocrinol. 2011;46(1):R1-9. https://doi.org/10.1677/JME-10-0122.

79. Zuo W, Zhang W, Chen N-H. Sexual dimorphism in cerebral ischemia injury. Eur J Pharmacol. 2013;711(1-3):73-9. https://doi.org/10.1016/j.ejphar.2013.04.024.

80. Chisholm NC, Sohrabji F. Astrocytic response to cerebral ischemia is influenced by sex differences and impaired by aging. Neurobiol Dis. 2016;85:245-53. https://doi.org/10.1016/j.nbd.2015.03.028.

81. Zwain IH, Yen SSC. Neurosteroidogenesis in Astrocytes, Oligodendrocytes, and Neurons of Cerebral Cortex of Rat Brain. Endocrinology. 1999;140(8):3843-52. https://doi.org/10.1210/endo.140.8.6907.

82. Blurton-Jones $\mathrm{M}$, Tuszynski MH. Reactive astrocytes express estrogen receptors in the injured primate brain. Journal of Comparative Neurology. 2001;433(1):115-23. https://doi.org/10.1002/cne.1129.

83. Saldanha CJ, Duncan KA, Walters BJ. Neuroprotective actions of brain aromatase. Front Neuroendocrinol. 2009;30(2):106-18. https://doi.org/10.1016/j.yfrne.2009.04.016.

84. Azcoitia I, Santos-Galindo M, Arevalo MA, Garcia-Segura LM. Role of astroglia in the neuroplastic and neuroprotective actions of estradiol: Estradiol and astroglia. Eur J Neurosci. 2010;32(12):19952002. https://doi.org/10.1111/j.1460-9568.2010.07516.x.

85. Barreto GE, Santos-Galindo M, Garcia-Segura LM. Selective estrogen receptor modulators regulate reactive microglia after penetrating brain injury. Front Aging Neurosci. 2014;6:132. https://doi.org/10.3389/fnagi.2014.00132.

86. Ma Y, Guo H, Zhang L, Tao L, Yin A, Liu Z, et al. Estrogen replacement therapy-induced neuroprotection against brain ischemia-reperfusion injury involves the activation of astrocytes via estrogen receptor $\beta$. Sci Rep. 2016;6(1):21467. https://doi.org/10.1038/srep21467.

87. Walker ML, Herndon JG. Menopause in nonhuman primates? Biol Reprod. 2008;79(3):398-406. https://doi.org/10.1095/biolreprod.108.068536.

88. Takahashi TA, Johnson KM. Menopause. Med Clin North Am. 2015;99(3):521-34. https://doi.org/10.1016/j.mcna.2015.01.006.

89. Su HI, Freeman EW. Hormone changes associated with the menopausal transition. Minerva Ginecol. 2009;61(6):483-9.

90. Santoro N, Randolph JF. Reproductive hormones and the menopause transition. Obstet Gynecol Clin North Am. 2011;38(3):455-66. https://doi.org/10.1016/j.ogc.2011.05.004. 
91. Keverne EB, Michael RP. Annual changes in the menstruation of rhesus monkeys. J Endocrinol. 1970;48(4):669-70. https://doi.org/10.1677/joe.0.0480669.

92. Van Wagenen G. Vital statistics from a breeding colony. Reproduction and pregnancy outcome in Macaca mulatta. J Med Primatol. 1972;1 (1):2-28.

93. Walker ML. Menopause in female rhesus monkeys. Am J Primatol. 1995;35(1):59-71. https://doi.org/10.1002/ajp.1350350106.

94. Hotchkiss J, Atkinson LE, Knobile E. Time Course of Serum Estrogen and Luteinizing Hormone (LH) Concentrations During the Menstrual Cycle of the Rhesus Monkey. Endocrinology. 1971;89(1):17783. https://doi.org/10.1210/endo-89-1-177.

95. Bellino FL, Wise PM. Nonhuman Primate Models of Menopause Workshop1. Biol Reprod. 2003;68(1):10-8. https://doi.org/10.1095/biolreprod.102.005215.

96. Gargano JW, Reeves MJ, Paul Coverdell National Acute Stroke Registry Michigan Prototype Investigators. Sex differences in stroke recovery and stroke-specific quality of life: results from a statewide stroke registry. Stroke. 2007;38(9):2541-8. https://doi.org/10.1161/STROKEAHA.107.485482.

97. Starosta M, Miller E, Redlicka J, Kostka J. Analysis of upper limb muscle strength in the early phase of brain stroke. Acta of Bioengineering and Biomechanics; 03/2017; ISSN 1509-409X. 2017; https://doi.org/10.5277/ABB-00649-2016-02.

98. Di Carlo A, Lamassa M, Baldereschi M, Pracucci G, Basile AM, Wolfe CDA, et al. Sex differences in the clinical presentation, resource use, and 3-month outcome of acute stroke in Europe: data from a multicenter multinational hospital-based registry. Stroke. 2003;34(5):1114-9. https://doi.org/10.1161/01.STR.0000068410.07397.D7.

99. Kapral MK, Fang J, Hill MD, Silver F, Richards J, Jaigobin C, et al. Sex differences in stroke care and outcomes: results from the Registry of the Canadian Stroke Network. Stroke. 2005;36(4):809-14. https://doi.org/10.1161/01.STR.0000157662.09551.e5.

100. Reeves MJ, Bushnell CD, Howard G, Gargano JW, Duncan PW, Lynch G, et al. Sex differences in stroke: epidemiology, clinical presentation, medical care, and outcomes. Lancet Neurol. 2008;7(10):915-26. https://doi.org/10.1016/S1474-4422(08)70193-5.

101. Kim J-S, Lee K-B, Roh H, Ahn M-Y, Hwang H-W. Gender differences in the functional recovery after acute stroke. J Clin Neurol. 2010;6(4):183-8. https://doi.org/10.3988/jcn.2010.6.4.183.

102. Quinn TJ, Langhorne P, Stott DJ. Barthel index for stroke trials: development, properties, and application. Stroke. 2011;42(4):1146-51. https://doi.org/10.1161/STROKEAHA.110.598540.

103. Sreekrishnan A, Leasure AC, Shi F-D, Hwang DY, Schindler JL, Petersen NH, et al. Functional Improvement Among Intracerebral Hemorrhage (ICH) Survivors up to 12 Months Post-injury. Neurocrit Care. 2017;27(3):326-33. https://doi.org/10.1007/s12028-017-0425-4.

104. Sue-Min L, Duncan PW, Dew P, Keighley J. Sex Differences in Stroke Recovery. Prev Chronic Dis. 2005;2(3). Available from: https://www.ncbi.nlm.nih.gov/pmc/articles/PMC1364522/. 
105. Baker K, Cano SJ, Playford ED. Outcome Measurement in Stroke: A Scale Selection Strategy. Stroke. 2011;42(6):1787-94. https://doi.org/10.1161/STROKEAHA.110.608505.

106. Jiang N, Chopp M, Stein D, Feit $H$. Progesterone is neuroprotective after transient middle cerebral artery occlusion in male rats. Brain Res. 1996;735(1):101-7. https://doi.org/10.1016/00068993(96)00605-1.

107. Chen J, Chopp M, Li Y. Neuroprotective effects of progesterone after transient middle cerebral artery occlusion in rat. J Neurol Sci. 1999;171(1):24-30. https://doi.org/10.1016/S0022-510X(99)00247-6.

108. Cervantes M, González-Vidal MD, Ruelas R, Escobar A, Moralí G. Neuroprotective Effects of Progesterone on Damage Elicited by Acute Global Cerebral Ischemia in Neurons of the Caudate Nucleus. Arch Med Res. 2002;33(1):6-14. https://doi.org/10.1016/S0188-4409(01)00347-2.

109. Xu F-F, Sun S, Ho ASW, Lee D, Kiang KMY, Zhang X-Q, et al. Effects of progesterone vs. dexamethasone on brain oedema and inflammatory responses following experimental brain resection. Brain Inj. 2014;28(12):1594-601. https://doi.org/10.3109/02699052.2014.943289.

\section{Tables}

Table 1 Subject data and individual data on estrogen levels, lesion volume, and pre-operative latency. 


\begin{tabular}{|llllll|}
\hline Monkeys & $\begin{array}{l}\text { Age at } \\
\text { Surgery }\end{array}$ & $\begin{array}{l}\text { Estrogen Level at Time } \\
\text { of Surgery }(\mathrm{pg} / \mathrm{ml})\end{array}$ & $\begin{array}{l}\text { Lesion } \\
\text { Volume }\end{array}$ & $\begin{array}{l}\text { Preoperative } \\
\text { Latency - Large } \\
\text { Well }\end{array}$ & $\begin{array}{l}\text { Preoperative } \\
\text { Latency - Small } \\
\text { Well }\end{array}$ \\
\hline AM323 & 23.67 & 88.3 & 34.03 & 1.10 & 1.15 \\
\hline AM331 & 26.08 & 52.4 & 52.18 & 2.20 & 1.77 \\
\hline AM335 & 20.33 & 66.3 & 25.81 & 1.53 & 1.25 \\
\hline AM337 & 24.33 & 31.7 & 25.83 & 0.89 & 1.08 \\
\hline AM339 & 21.42 & 55.3 & 31.27 & 1.41 & 1.07 \\
\hline Mean & 23.17 & 58.80 & & & 1.26 \\
\hline SE & 1.03 & 9.26 & 33.82 & 1.43 & 0.13 \\
\hline SM006 & 17.17 & n/a & 4.86 & 0.22 & \\
\hline SM007 & 17 & n/a & & & 1.75 \\
\hline SM010 & 21.08 & n/a & 27.83 & 1.82 & 1.97 \\
\hline SM027 & 12 & n/a & 68.65 & 2.11 & 1.10 \\
\hline Mean & 16.81 & n/a & 59.48 & 0.99 & 0.91 \\
\hline SE & 1.66 & n/a & 98.07 & 1.29 & $\mathbf{0 . 2 5}$ \\
\hline
\end{tabular}

Table 2 Mean latency data for each monkey during the post-operative period. 


\begin{tabular}{|c|c|c|c|c|c|c|}
\hline \multirow[b]{2}{*}{ Monkeys } & \multicolumn{2}{|c|}{$\begin{array}{l}1^{\text {st }} \text { Five Days of Post- } \\
\text { operative Testing }\end{array}$} & \multicolumn{2}{|c|}{$\begin{array}{l}\text { Difference Between Last } 5 \text { Days } \\
\text { Pre-operative and First } 5 \text { Days Post- } \\
\text { operative Testing }\end{array}$} & \multicolumn{2}{|c|}{ All 12 Weeks Testing } \\
\hline & $\begin{array}{l}\text { Mean } \\
\text { Latency - } \\
\text { Large } \\
\text { Well }\end{array}$ & $\begin{array}{l}\text { Mean } \\
\text { Latency - } \\
\text { Small } \\
\text { Well }\end{array}$ & $\begin{array}{l}\text { Mean Latency - } \\
\text { Large Well }\end{array}$ & $\begin{array}{l}\text { Mean Latency - } \\
\text { Small Well }\end{array}$ & $\begin{array}{l}\text { Mean } \\
\text { Latency - } \\
\text { Large } \\
\text { Well }\end{array}$ & $\begin{array}{l}\text { Mean } \\
\text { Latency - } \\
\text { Small } \\
\text { Well }\end{array}$ \\
\hline AM323 & 1.62 & 1.67 & 0.52 & 0.52 & 1.46 & 1.46 \\
\hline AM331 & 3.10 & 3.49 & 0.9 & 1.72 & 2.64 & 2.62 \\
\hline AM335 & 2.40 & 1.72 & 0.87 & 0.47 & 1.92 & 1.55 \\
\hline AM337 & 1.28 & 1.42 & 0.39 & 0.34 & 1.00 & 1.04 \\
\hline AM339 & 1.60 & 1.16 & 0.19 & 0.09 & 1.52 & 1.19 \\
\hline Mean & 2.00 & 1.89 & 0.57 & 0.63 & 1.71 & 1.57 \\
\hline SE & 0.33 & 0.41 & 0.14 & 0.28 & 0.27 & 0.28 \\
\hline SM006 & 3.53 & 3.19 & 1.71 & 1.44 & 2.42 & 2.58 \\
\hline SM007 & 5.42 & 5.60 & 3.31 & 3.63 & 6.00 & 4.76 \\
\hline SM010 & 2.03 & 1.37 & 1.04 & 0.27 & 1.45 & 1.33 \\
\hline SM027 & 3.25 & 2.85 & 1.96 & 1.94 & 2.05 & 1.62 \\
\hline Mean & 3.56 & 3.25 & 2.01 & 1.82 & 2.98 & 2.57 \\
\hline SE & 0.70 & 0.88 & 0.48 & 0.70 & 1.03 & 0.78 \\
\hline
\end{tabular}

Figures 

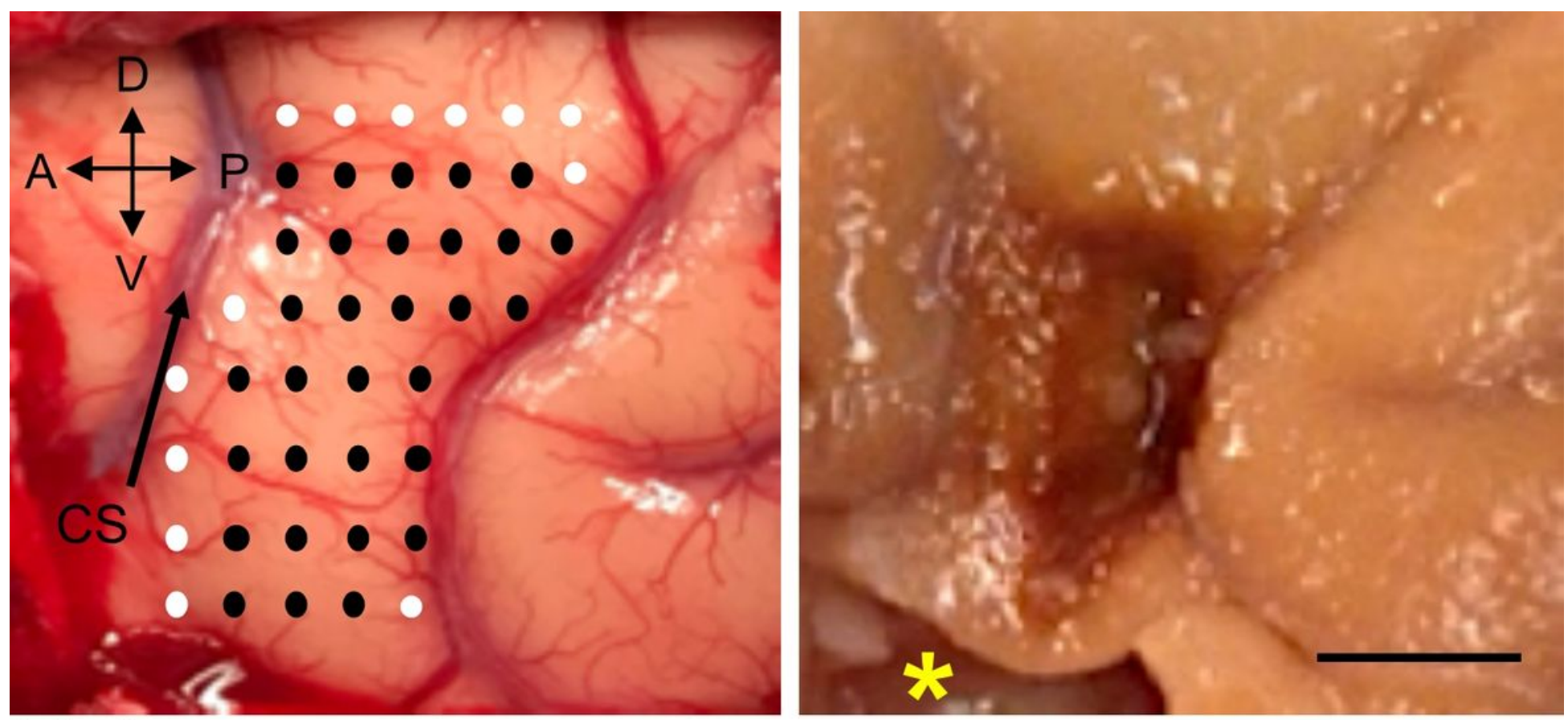

\section{Male}
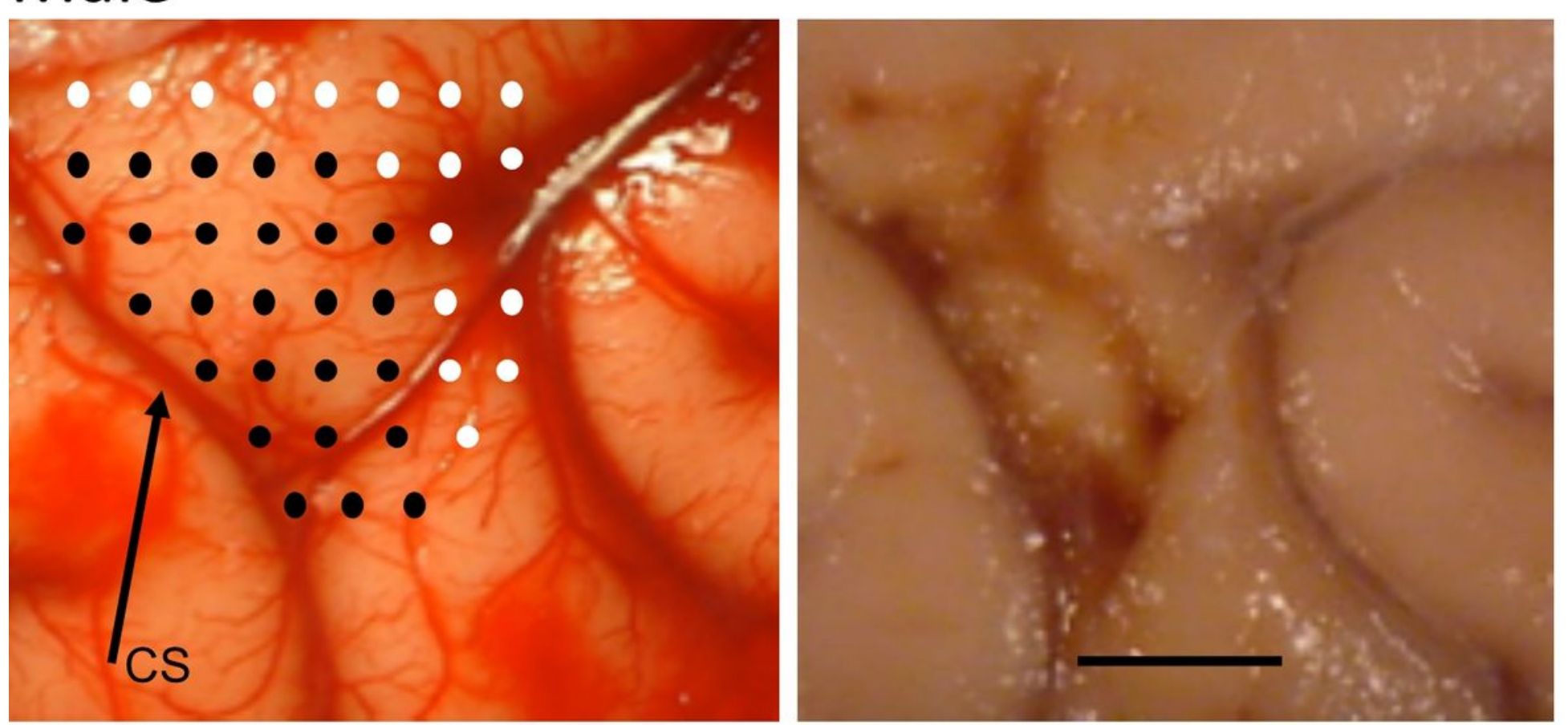

\section{Figure 1}

Representative photographs of cortical maps and lesions. Photos showing the stimulation sites on the hand representation maps and the final lesion after perfusion for one female monkey (top row) and one male monkey (bottom row). On the hand representation maps, the black circles represent stimulation sites that generated a positive response in the hand or digits and the white circles represent stimulation sites that did not generate a positive response. * - area where a fresh tissue sample was extracted at perfusion. CS - Central Sulcus. Scale bar $=5 \mathrm{~mm}$ 

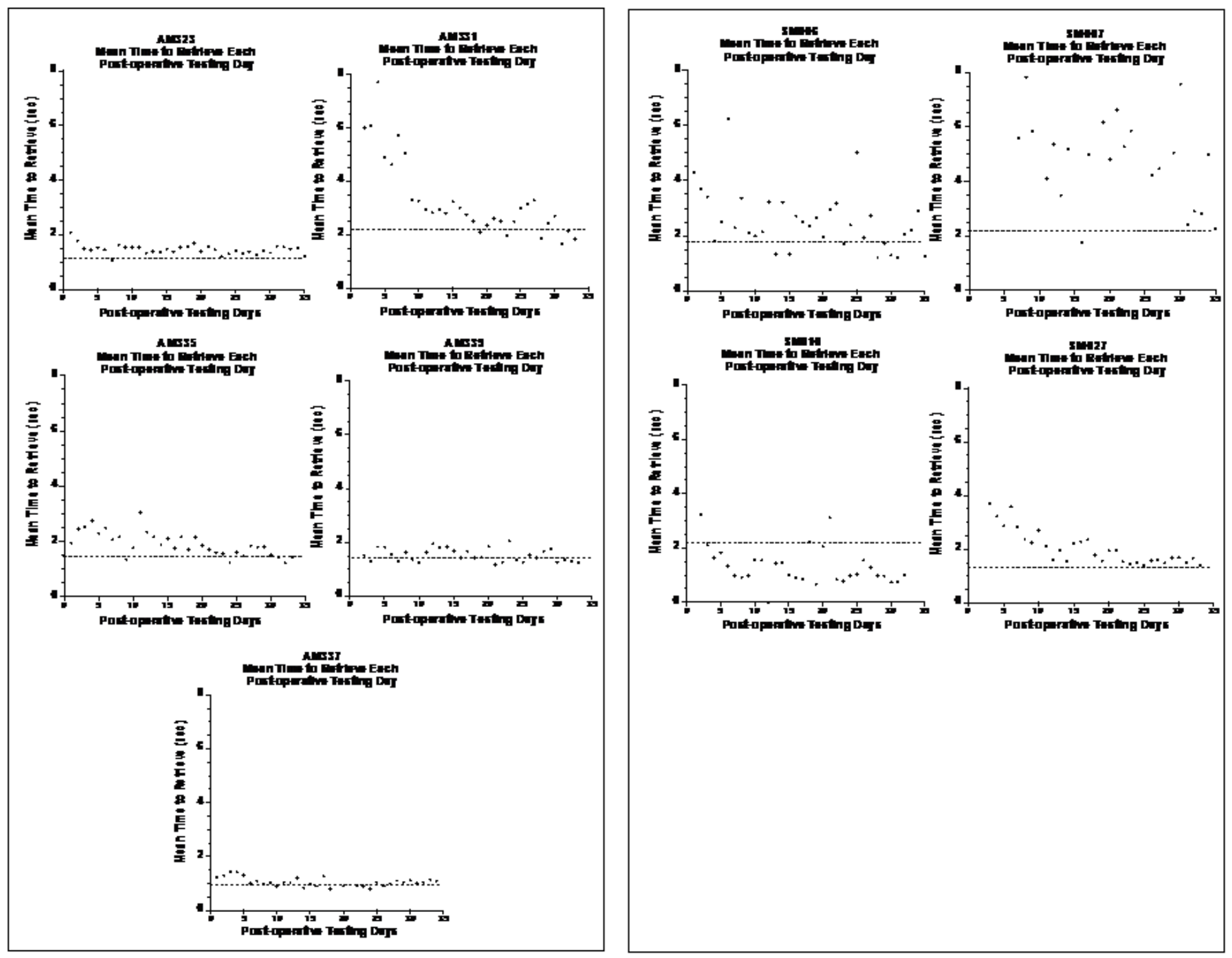

Figure 2

Mean time to retrieve the food reward each day during the 12-week post-operative period. Graphs of the daily mean time to retrieve a food reward from the large well with the impaired hand across the postoperative recovery period. The dashed line represents the mean time to retrieve the food reward over the last five days of the pre-operative training. Each data point (black dots) represents the mean time to retrieve for each post-operative day. 


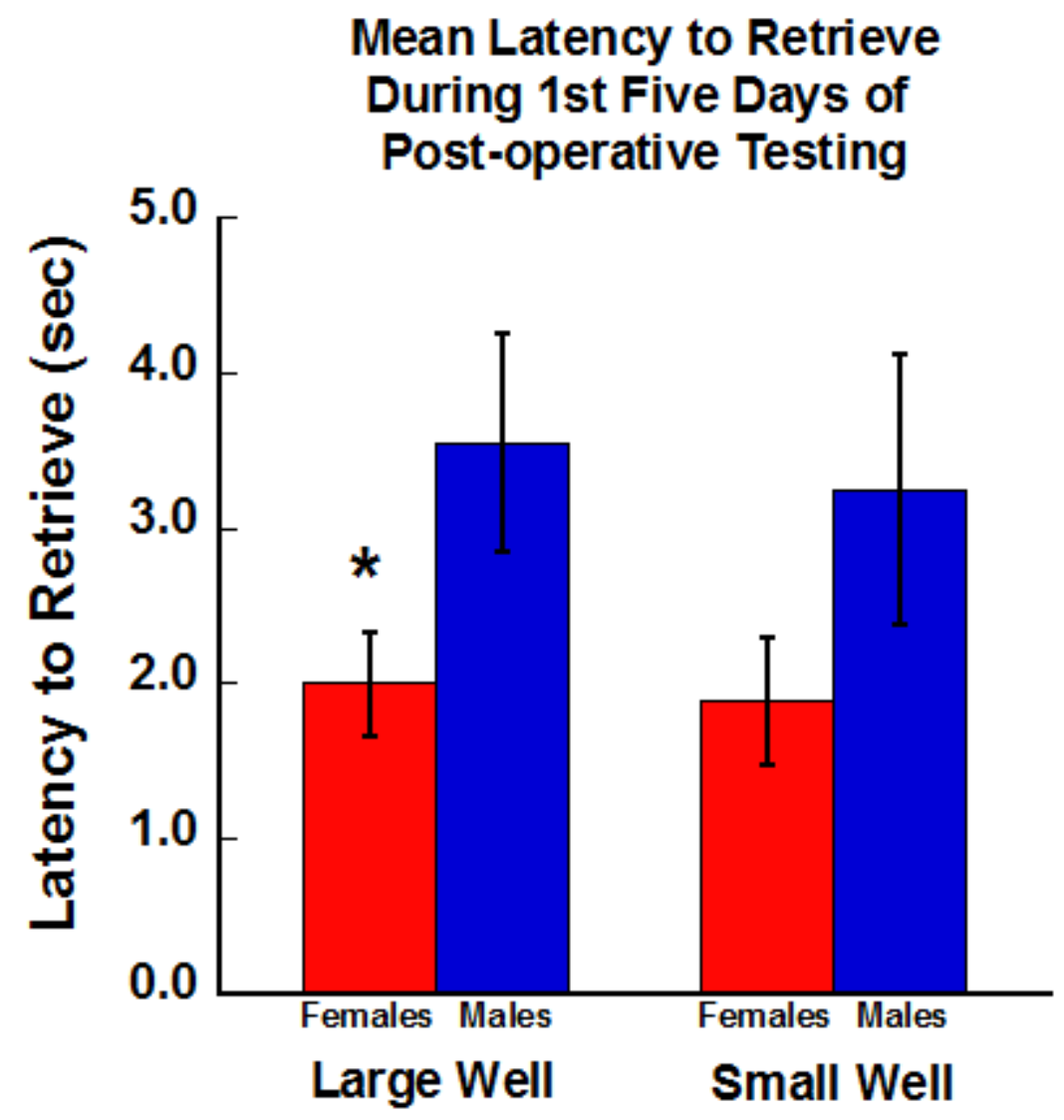

Figure 3

Mean latency to retrieve during the first five days of post-operative testing. Graph of mean latency to retrieve the food reward from each of the two wells (large and small) during the first five days of postoperative testing. Female monkeys retrieve the reward at a faster rate than males during this early postoperative period on the large well. Error bars $=$ Standard Error. 


\section{Uean Latency to Retuieve for Last 5 Days \\ Preoperative and 1st 5 Days Post-operative Testing \\ Sndinel}

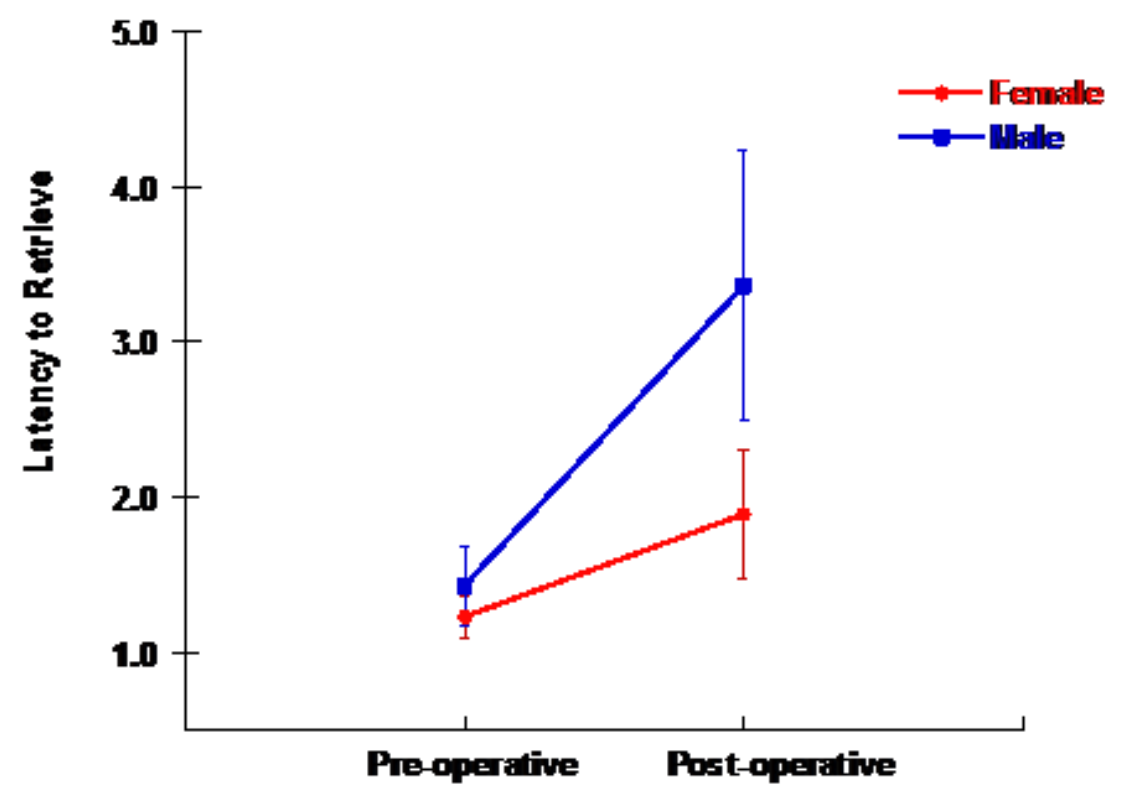

Wein Latency to Retuieve for Last 5 Days

Pre-operative and 1st 5 Days Post-operative Teting Lage We

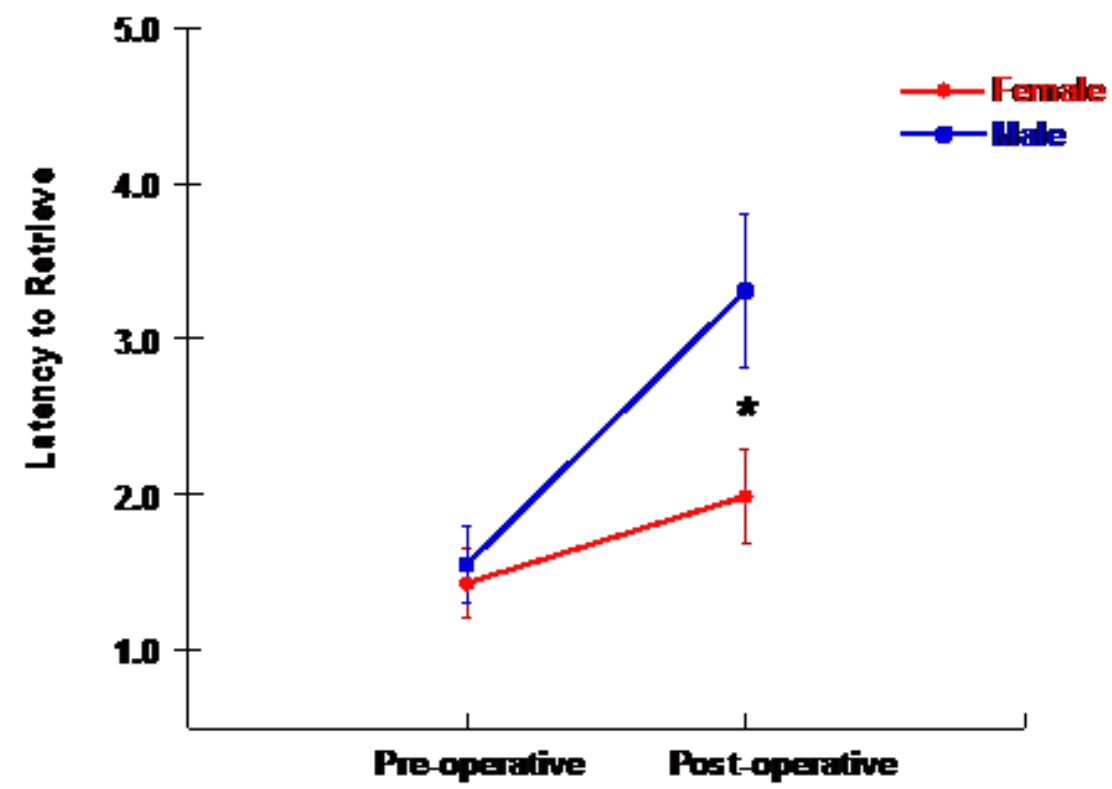

Figure 4

Female monkeys experienced less severe deficits in latency to retrieve after injury than males. A. Graph of latency to retrieve for the last 5 days of pre-operative testing and the first 5 days of post-operative testing on the small well for male and female monkeys. Error bars = Standard Error. B. Graph of latency to retrieve for the last 5 days of pre-operative testing and the first 5 days of post-operative testing on the large well for male and female monkeys. Error bars = Standard Error. 

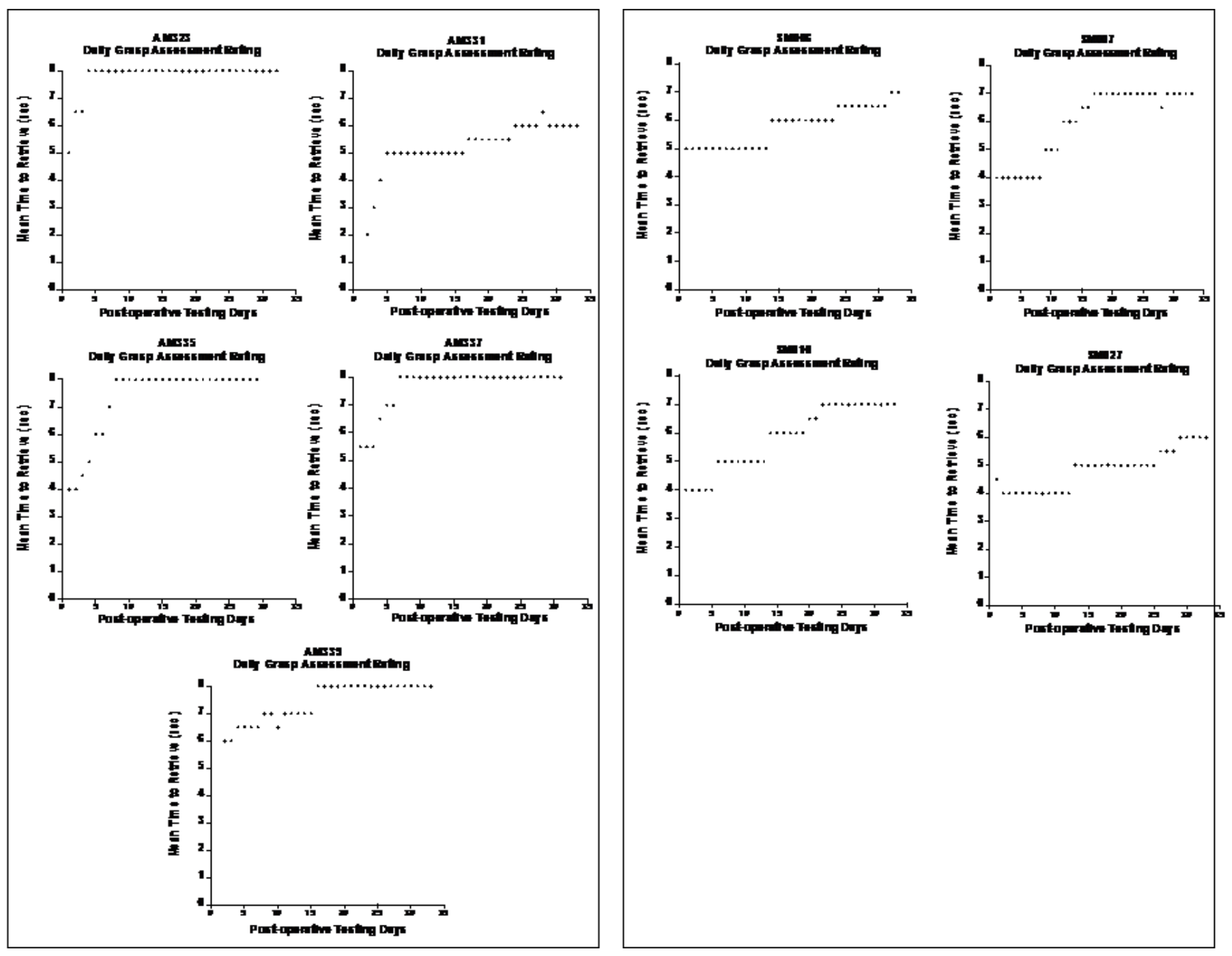

Figure 5

Mean grasp rating each day during the post-operative period. Graphs of the daily mean grasp rating of the impaired hand across the post-operative recovery period for each monkey. A score of 8 represents a normal grasp pattern that was documented during pre-operative training . Each data point (black dots) represents the mean grasp pattern score for each post-operative day. 


\section{Overall Mean Grasp Rating}

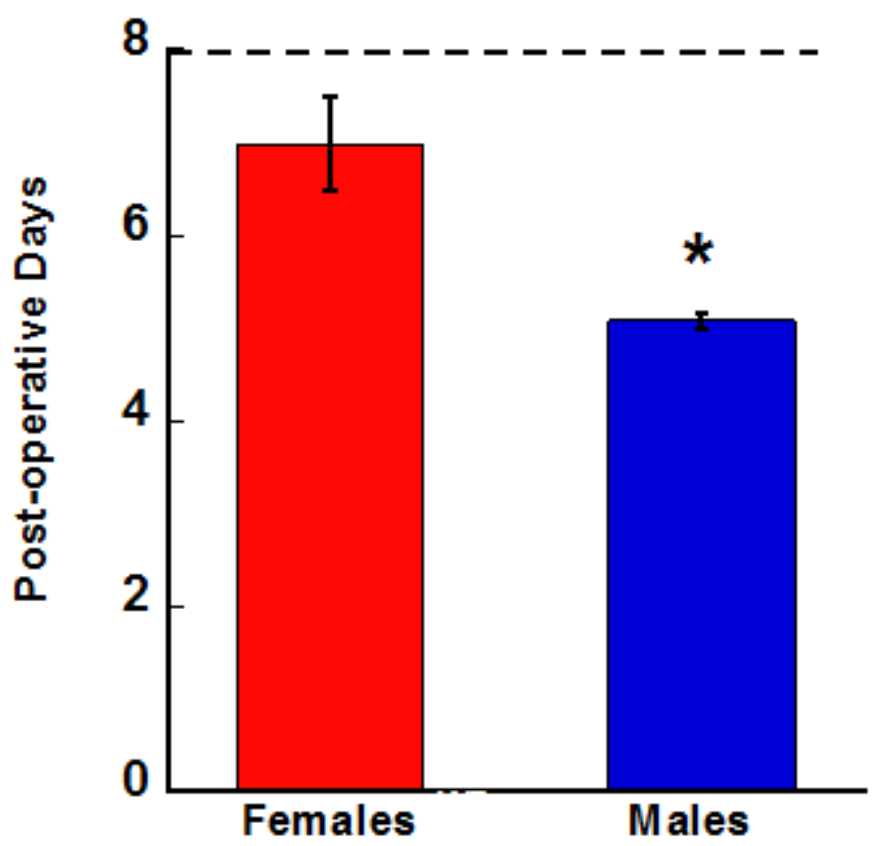

\section{Figure 6}

Female monkeys achieved an overall higher grasp rating than male monkeys. Graph of the mean grasp rating for each group. A score of 8 represents a return to pre-operative grasp patterns (dashed line). Error bars $=$ Standard Error. 
Days to Retum to Pre-operative Grasp

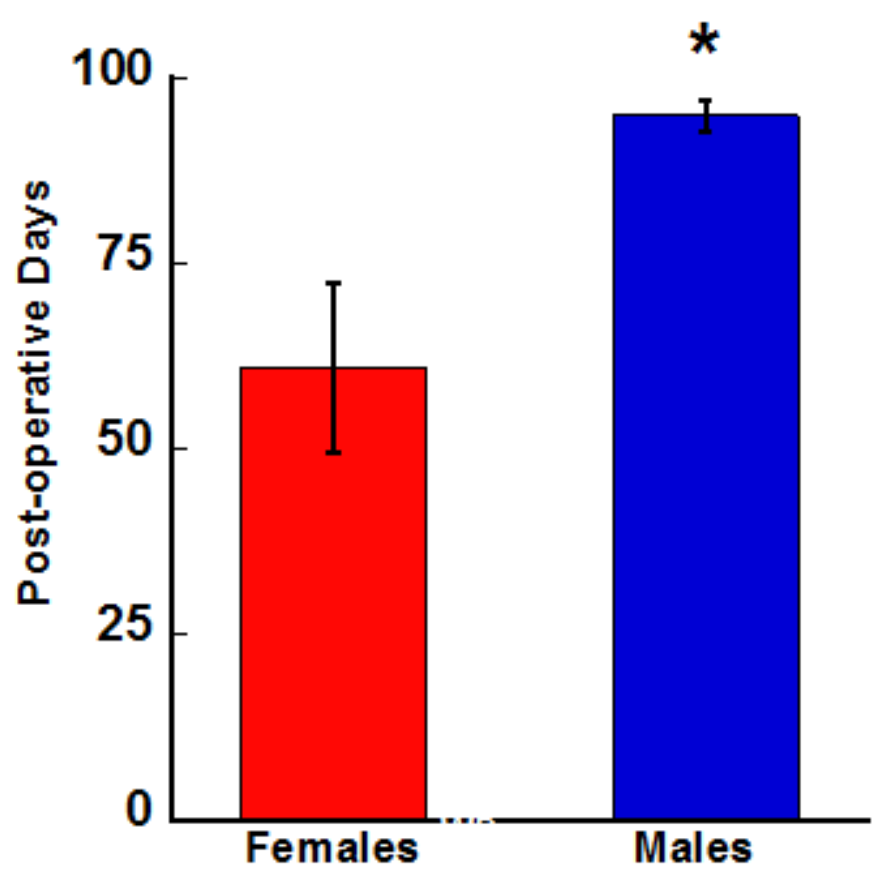

Figure 7

Female monkeys reached their highest grasp rating in fewer days than male monkeys. Graph of the mean number of days to return to pre-operative grasp patterns for each group. Error bars $=$ Standard Error.

\section{Recovered Grasp}

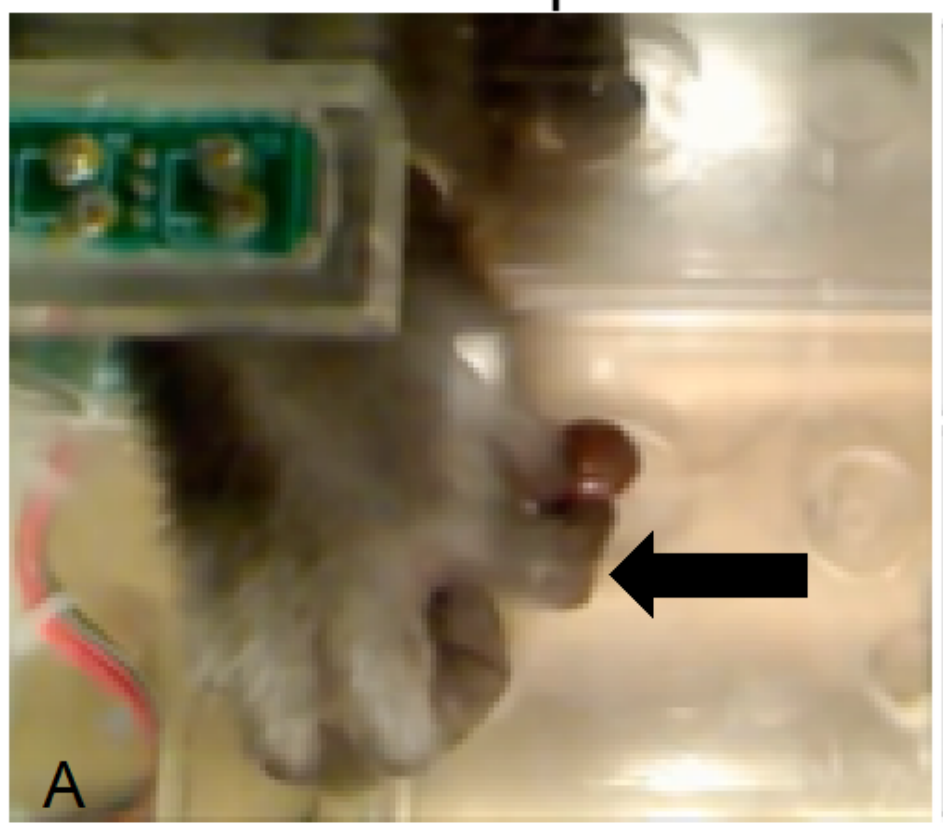

\section{Compensatory Grasp}

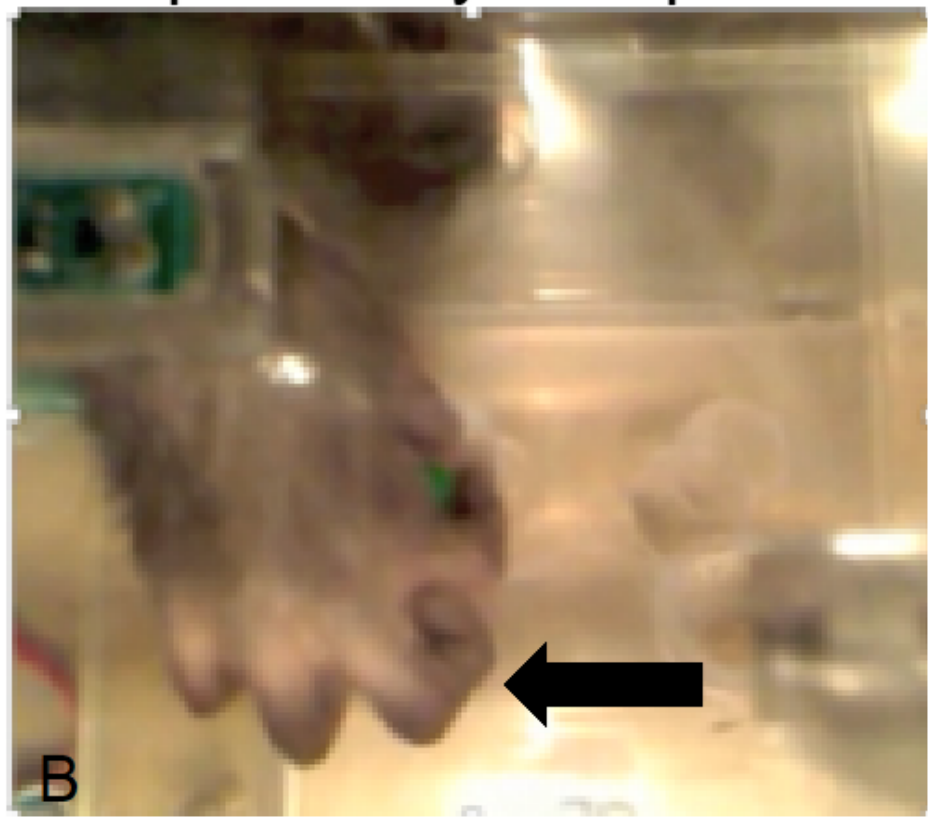

Figure 8 
Representative images of post-operative grasp patterns. A. Image shows recovered finger-thumb grasp of a monkey with isolated digit action and no evidence of "mass action" of the digits or compensatory scooping. Arrow in A shows precise finger-thumb grasp. B. Image shows compensatory "scooping" involving all fingers of a monkey. The fingers work together to retrieve the food reward, a grasp that is referred to as "mass action" of digits. Arrow in B shows fingers scooping candy into palm of the hand. 